\title{
The Effects of Two Bathing Methods on the Time of Separation of Umbilical Cord in Term Babies in Turkey
}

\author{
Tulay Ayyildiz ${ }^{1, *}$; Hulya Kulakci ${ }^{2}$; Ferruh Niyazi Ayoglu ${ }^{3}$; Nihal Kalinci ${ }^{4}$; Funda Veren ${ }^{2}$ \\ ${ }_{1}^{1}$ Department of Pediatric Nursing, Zonguldak School of Nursing, Bulent Ecevit University, Zonguldak, Turkey \\ 2 Department of Public Health Nursing, Zonguldak School of Nursing, Bulent Ecevit University, Zonguldak, Turkey \\ 3 Department of Public Health Medical, Bulent Ecevit University, Zonguldak, Turkey \\ ${ }^{4}$ Newborn Service Nursing, Zonguldak Maternity and Children's Hospital, Zonguldak, Turkey \\ ${ }^{*}$ Corresponding Author: Tulay Ayyildiz, Department of Pediatric Nursing, Zonguldak School of Nursing, Bulent Ecevit University, Zonguldak, Turkey. Tel: +90-3722613377, Fax: +90- \\ 3722613399, E-mail: tayyildiz@mynet.com
}

Received: April 1, 2014; Revised: May 5, 2014; Accepted: June 18, 2014

\begin{abstract}
Background: Umbilical cord infection developing subsequent to bacterial colonization is one of the outstanding reasons of newborn mortality and morbidity in underdeveloped and developing countries

Objectives: This study aimed to evaluate the influence of sponge and tub bathing methods on umbilical cord separation time in full term babies in Turkey.

Patients and Methods: This quasi-experimental and randomized controlled study was performed on 100 healthy term newborn babies and their mothers. One-hundred full-term babies (51 sponge bathing, 49 tub bathing) born at a state hospital between 14.03.2013 and 18.05.2013 with gestational age of 38-42 weeks, weighing 2500 grams and above and met the selection criteria were included as the study sample. Two booklets were prepared about sponge bathing and tub bathing. Mothers were instructed about sponge bathing and tub bathing, umbilical cord care in prenatal and postnatal periods. The first postnatal visit was performed at the hospital. Home visits and telephone calls were continued until the day of cord separation. Number, percent, mean and standard deviation values, qui-square and Mann-Whitney U tests were used for data assessment.

Results: The time of separation of umbilical cord in babies who were given sponge bathing (6.1 \pm 1.4$)$ was shorter compared to those given tub bathing $(8.3 \pm 2.5)(\mathrm{P}<0.005)$.

Conclusions:Since wetting of umbilical cord during tub bathing delays the separation of umbilical cord, sponge bathing is recommended for newborns until the umbilical cord falls off.
\end{abstract}

Keywords:Newborn; Umbilical Cord; Nursing Care; Home Care Services

\section{Background}

More than a half million newborns are estimated to die annually from serious neonatal infections, accounting for about $15 \%$ of all neonatal deaths globally $(1,2)$. Around $75 \%$ of neonatal deaths occur during the first week of life, with most in the first 48 hours (3). In populations with very high neonatal mortality, up to a half of neonatal deaths may have an infectious cause $(4,5)$.

Umbilical cord is an important gateway for infections, since it includes necrotic tissue. The umbilical cord infection developing subsequent to bacterial colonization is one of the outstanding reasons of newborn mortality and morbidity in underdeveloped and developing countries (6-10).

The main objective of a nurse working in newborn care is to prevent infection. Therefore, one of the most important practices in newborn care is umbilical cord care. Umbilical cord and the surrounding tissue should be frequently checked for signs of skin infection (11). Proper skin care for newborn, keeping the umbilical cord clean and providing fast drying are crucial in the prevention of umbilical cord infections. Umbilical cord falls off within nearly 7-15 days in healthy term newborns. A few bleeding may occur after it falls off (12).

The most suitable time for umbilical cord care in babies is bathing time (13). However, there are different opinions about whether baby should be bathed until the umbilical cord falls off or which bathing method is preferred. Traditionally, sponge bathing is preferred for daily routine care until the umbilical cord falls off, and tub bathing is preferred after the cord is fallen off (11). The American Academy of Pediatrics stated that tub bathing performed before the separation of umbilical cord may leave the umbilical cord wet and predispose infection by delaying its separation; thus, it is required to make sponge bathing until the umbilical cord falls off (14). Contrary to this view, tub bathing is recommended for term newborns in the guideline for newborn skin care, developed by the Association of Women's Health, Obstetric and Neonatal Nurses (AWHONN)/National Association of Neonatal Nurses (15).

Copyright (C) 2015, Iranian Red Crescent Medical Journal. This is an open-access article distributed under the terms of the Creative Commons Attribution-NonCommercial 4.0 International License (http://creativecommons.org/licenses/by-nc/4.0/) which permits copy and redistribute the material just in noncommercial usages, provided the original work is properly cited. 
There were many studies evaluating the effect of different solutions such as antiseptic solutions, human milk, water $(13,16,17)$ and factors of maternal and newborn (18) on the time of separation of umbilical cord and development of infection. While there are limited studies evaluating the effect of performed bathing method on the time of separation of the umbilical cord worldwide (19-21), there are no studies performed in Turkey.

\section{Objectives}

This study aimed to evaluate the effects of sponge and tub bathing methods on the time of separation of the umbilical cord in term babies in Turkey.

\section{Patients and Methods}

\subsection{Study Design}

This quasi-experimental and randomized controlled study was performed on 100 healthy term newborn babies and their mothers at Zonguldak Maternity and Children's Hospital in Zonguldak between 14.03.201318.05.2013.

\subsection{Sample Selection Criteria}

\subsubsection{Inclusion Criteria}

Babies who were not born as a result of multiple and high risk pregnancies, whose mothers did not have a chronic-systemic disease, hepatitis, acquired immunodeficiency syndrome and genital infection, born between 3842 weeks, not undergone any intervention such as forceps and vacuum extraction during the delivery, did not show an early membrane rupture, weighted above $2.500 \mathrm{~kg}$, whose Apgar scores were between 7-10, did not have a congenital defect, did not have a dermatological problem, did not develop a physiological or pathological jaundice after delivery and were living in Zonguldak City center.

\subsubsection{Exclusion Criteria}

Babies who were born as a result of multiple and high risk pregnancies, whose mothers had a chronic-systemic disease, hepatitis, acquired immunodeficiency syndrome and genital infection, born before 38 weeks, undergone interventions such as forceps and vacuum extraction during the delivery, showed an early membrane rupture, weighted below $2.500 \mathrm{~kg}$, whose Apgar scores were below 7, had a congenital defect, had a dermatological problem, developed a physiological or pathological jaundice after delivery and were not living in Zonguldak City center.

\subsection{Setting and Samples}

The study was conducted at Zonguldak Maternity and Children's Hospital. The hospital is in Zonguldak city center located in Western Black Sea region of Turkey. It is a governmental and specialized hospital, which provides maternity and pediatrics' services and has 135 beds.

In this study, we did not use any sampling method. We wanted to reach all newborn babies and their mothers eligible for selection criteria and whose families agreed to participate in the study between 14.03.2013 and 18.05.2013. In accordance with these criteria, 109 (56 sponge bathing, 53 tub bathing) healthy term newborn babies and their mothers participated in the study. The study was completed on 100 babies and their mothers (49 sponge bathing, 51 tub bathing), because four of newborns were given phototherapy due to physiological jaundice during the study and five mothers of newborns did not agree to complete the study.

\subsection{Data Collection}

Descriptive Characteristics Data Form was used for data collection by the researchers in accordance with the literature (18). There were 20 questions within the form including descriptive information regarding mother, father and newborn, and 12 questions including information for mothers regarding umbilical cord and skin care and subject-oriented applications.

Two booklets about sponge and tub bathing were prepared for the study. These booklets prepared for sponge and tub bathing for newborn babies included the materials required for sponge and tub bathing, appropriate room temperature, place for bathing, appropriate time, how to give bath, order of bath, considerations for bathing, practice after bathing, cleaning of genital regions and umbilical cord care (70\% alcohol was used in umbilical cord care in the both groups) $(11,12)$. Care was taken to make the topics simple and understandable for mothers.

Preliminary practice with Descriptive Characteristics Data Form and the booklets for sponge (with 10 mothers) and tub bathing (with 10 mothers) was performed by interviewing 20 mothers before starting the study. After preliminary practice, it was determined that Descriptive Characteristics Data Form was applicable and the booklets for sponge and tub bathing could be easily understood.

The study data was collected by the researchers. Researchers conducted the study as two groups, including family health center and hospital. Family health center group detected mothers who were within 37th week of pregnancy in the family health centers and mothers were visited at their homes and informed about the study. Informed consent forms were filled by parents who agreed to participate in the study.

The mothers who were willing to participate in the study were given Descriptive Characteristics Data Form and asked which bathing method they wanted to use after having information about both bathing methods. Mothers were revisited at 38, 39 and 40th week of pregnancy. Mothers were informed about the bathing method they have chosen and given a practice booklet at 
Ayyildiz T et al.

these visits. Mothers in the both groups were told to bath their babies every two days. The first visit after delivery was performed by hospital group at the hospital. One of the researchers went to babies' home and observed their umbilical cord at 2, 4, 6, 8, 10, 12, 14 and 16th days after delivery. She also observed any signs of umbilical cord infection during home visits including swelling, erythema, discharge and odor. The presence of one of these signs was considered as the risk of infection. Mothers were told to refer to hospital if they observed any of these signs and given the contact details of the researchers. Home visits were ended after the umbilical cord was fallen off.

\subsection{Ethical Considerations}

To conduct the study, written approval was received from Administration of Zonguldak Maternity and Children's Hospital (B.10.1.TKH.4.67.N.67.0.01/127). All mothers were informed about the purpose of study and the research process and an informed consent was taken from mothers who agreed to participate in the study. During the study, patient privacy was maintained.

\subsection{Data Analysis}

Statistical analysis was performed using SPSS 18.0 software (PASW Statistics for Windows, Chicago: SPSS Inc) software (vs 18.0). Compliance with normal distribution for numerical variables was assessed by Shapiro-Wilk test. In descriptive statistics, numerical data were expressed as mean \pm standard deviation (median, minimum-maximum) and categorical data were expressed as numbers and percentages.

The differences between the groups for categorical variables were assessed by Chi-Square test. Since parametric test assumptions were not met, Mann-Whitney U test was used to compare the two groups for numerical variables. $\mathrm{P}<0.05$ was considered as statistically significant.

\section{Results}

In Table 1, it is observed that there was no statistically significant difference between the two groups for education level of mother and father, employment status of mothers, father's occupation, family type and heating mode of the house $(\mathrm{P}>0.05)$.

\begin{tabular}{|c|c|c|c|c|}
\hline \multirow[t]{2}{*}{ Characteristics $^{\mathrm{a}}$} & \multirow[t]{2}{*}{ Sponge Bathing $(n=49)$} & \multirow[t]{2}{*}{ Tub bathing $(n=51)$} & \multicolumn{2}{|c|}{ Test Value } \\
\hline & & & $\mathrm{x}^{2}$ & $\mathbf{P}$ \\
\hline Education level of mother & & & 3.71 & 0.15 \\
\hline Elementary school & $16(32.6)$ & $26(51.0)$ & & \\
\hline Secondary school & $22(45.0)$ & $15(29.4)$ & & \\
\hline Undergraduate and more & $11(22.4)$ & $10(19.6)$ & & \\
\hline Education level of father & & & 3.32 & 0.19 \\
\hline Elementary school & $12(24.5)$ & $18(35.3)$ & & \\
\hline Secondary school & $21(43.0)$ & $24(47.1)$ & & \\
\hline Undergraduate and more & $16(32.5)$ & $9(17.6)$ & & \\
\hline Employment status of mother & & & 2.30 & 0.12 \\
\hline Does not work & $34(69.4)$ & $42(82.4)$ & & \\
\hline Does work & $15(30.6)$ & $9(17.6)$ & & \\
\hline Father's occupation & & & 1.40 & 0.49 \\
\hline Officer & $8(16.3)$ & $10(19.6)$ & & \\
\hline Worker & $17(34.7)$ & $22(43.1)$ & & \\
\hline Self employed & $24(49.0)$ & $19(37.3)$ & & \\
\hline Family type & & & 0.15 & 0.69 \\
\hline Nuclear & $43(87.8)$ & $46(90.2)$ & & \\
\hline Large & $6(12.2)$ & $5(9.8)$ & & \\
\hline Heating mode & & & 0.03 & 0.85 \\
\hline Stove & $26(53.1)$ & $28(54.9)$ & & \\
\hline Central heating & $23(46.9)$ & $23(45.1)$ & & \\
\hline Characteristics ${ }^{b}$ & & & $\mathbf{U}$ & $\mathbf{p}$ \\
\hline Mother's age & $28.7 \pm 4.9(27,20-44)$ & $29.6 \pm 5.8(30,20-43)$ & 893.0 & 0.083 \\
\hline Father's age & $30.4 \pm 4.5(30,23-45)$ & $33.1 \pm 5.7(32,24-47)$ & 993.0 & 0.076 \\
\hline Age at first pregnancy & $24.7 \pm 3.8(24,19-38)$ & $24.3 \pm 4.1(22,15-41)$ & 949.0 & 0.058 \\
\hline Age at last pregnancy & $27.1 \pm 4.9(27,19-43)$ & $29.1 \pm 5.7(30,20-43)$ & 980.5 & 0.063 \\
\hline Number of children & $1.36 \pm 0.48(1,1-2)$ & $1.48 \pm 0.9(2,1-4)$ & 832.0 & 0.071 \\
\hline Which child & $1.40 \pm 0.49(1,1-2)$ & $1.90 \pm 1.0(2,1-4)$ & 880.0 & 0.056 \\
\hline Weight at birth, g & $3289.6 \pm 363.2(3250,2500-4100)$ & 1228.5 & 0.885 & \\
\hline
\end{tabular}


Ayyildiz T et al.

\begin{tabular}{|c|c|c|c|c|}
\hline \multirow[t]{2}{*}{ Characteristics } & \multirow{2}{*}{$\begin{array}{l}\text { Sponge Bathing } \\
\quad(n=49)\end{array}$} & \multirow{2}{*}{$\begin{array}{l}\text { Tub Bathing } \\
\quad(\mathbf{n}=\mathbf{5 1})\end{array}$} & \multicolumn{2}{|c|}{ Test Value } \\
\hline & & & $\mathbf{x}^{2}$ & $\mathbf{P}$ \\
\hline Gestational age, weeks & & & 2.987 & 0.22 \\
\hline $38-39.7$ & $4(8.2)$ & $8(15.7)$ & & \\
\hline $40-41.7$ & $45(91.8)$ & $43(84.3)$ & & \\
\hline Gender & & & 1.417 & 0.23 \\
\hline Female & $23(46.9)$ & $30(58.8)$ & & \\
\hline Male & $26(53.1)$ & $21(41.2)$ & & \\
\hline Mode of Delivery & & & 1.407 & 0.23 \\
\hline Natural delivery & $25(51.0)$ & $20(39.2)$ & & \\
\hline Cesarean & $24(49.0)$ & $31(60.8)$ & & \\
\hline
\end{tabular}

a Data are presented as No.(\%).

Table 3. Distribution of Time of Separation of Umbilical Cord in Babies Based on Bathing Method ${ }^{\mathrm{a}}$

\begin{tabular}{|c|c|c|c|c|}
\hline \multirow[t]{2}{*}{ Parameter } & \multirow{2}{*}{$\begin{array}{l}\text { Sponge Bathing } \\
\quad(n=49)\end{array}$} & \multirow{2}{*}{$\begin{array}{l}\text { Tub bathing } \\
\quad(\mathbf{n}=51)\end{array}$} & \multicolumn{2}{|c|}{ Test Value } \\
\hline & & & $\mathbf{U}$ & $\mathbf{p}$ \\
\hline The time of separation of the umbilical cord, day & $6.1 \pm 1.4(6,4-11)$ & $8.3 \pm 2.5(8,4-16)$ & 522.5 & 0.0001 \\
\hline
\end{tabular}

The time of separation of umbilical cord in babies who were given sponge bathing $(6.1 \pm 1.4)$ was shorter compared to those given tub bathing $(8.3 \pm 2.5)(\mathrm{P}<0.005)$. While no infection finding was found in 49 babies who were given sponge bathing, signs of discharge and erythema were seen in 2 of 51 babies (3.9\%) who were given tub bathing and directed to a health institution (Table 3 ).

Based on the bathing method, no statistically significant difference was found between the two groups for age of mother and father, age of mother at first and last pregnancy, number of children and baby's weight at birth (P>0.05).

When we compared gestational age, gender and mode of delivery based on bathing method, we could not find any statistically significant difference between the groups $(\mathrm{P}>0.05)$ (Table 2$)$.

\section{Discussion}

The purpose of this study was to evaluate the effect of sponge and tub bathing given to newborns on the time of separation of umbilical cord. It was based on the hypothesis that "the time of separation of umbilical cord in babies given sponge bathing is shorter than those given tub bathing". The study was completed on 100 babies and their mothers, including 49 sponge and 51 tub bathing. In the study, sponge and tub bathing groups showed similarities for education level of mothers and fathers, their ages, employment status and occupations, family type, mode of heating in the house, mother's age at first and last pregnancy, number of children, weight of baby at birth, gestational age, gender and mode of delivery.

Our findings showed that the time of separation of um- bilical cord in babies in the sponge bathing group was 6.1 \pm 1.4 (4-11) days and it was $8.3 \pm 2.5$ (4-16) days for babies in tub bathing group. The time of separation of umbilical cord in babies who were given sponge bathing was shorter than those given tub bathing and the difference between the two groups was statistically significant.

Since tub bathing performed before the separation of umbilical cord might keep umbilical cord wet, it might delay its separation and increase the risk of infection during traditional daily routine care for newborns. It is necessary to prefer sponge bathing until the umbilical cord falls off and tub bathing after it falls off (11).

Bryanton et al. conducted a randomized controlled study in obstetrics and gynecology unit of a hospital in Canada to compare the effects of traditional sponge and tub bathing methods on healing and infection of umbilical cord in healthy term babies. The study was performed on 102 healthy babies who were 37 weeks and more, and 2500 grams and more, and postpartum mothers who were physiologically and psychologically well. Mothers and babies enrolled in the study were classified as experimental tub bathing group $(n=51)$ and sponge bathing control group $(\mathrm{n}=51)$. Before the study, 33 nurses who were working in the unit were trained for bathing practice and evaluation of babies. Babies in the both groups were bathed twice. Healing of umbilical cord in babies was evaluated according to umbilical cord assessment scale. In case of infection development, umbilical cord was cultured. When considering the umbilicus assessment scores for umbilical cord healing, no difference was found between the groups and no infection was observed (19). 
In our study, it is believed that shorter time for the separation of umbilical cord in babies given sponge bathing was due to the fact that umbilical cord was not getting wet during sponge bathing. Umbilical cord was getting wet in babies given tub bathing and mothers could not dry it properly.

A local bad odor, erythema and discharge may occur around the umbilical cord of newborns due to development of infection, since it may remain wet and the separation of umbilical cord may be delayed (11). In this study, signs of infection on the umbilicus of babies given sponge and tub bathing were assessed. While no infection finding was observed in 49 babies in the sponge bathing group, discharge and erythema were seen on the umbilical cord in 2 of 51 babies (3.9\%) in the tub bathing group. However, no statistical analysis was performed since the number was insufficient.

In the studies by Henningsson et al., Hylen et al. and Bryanton et al. on healthy term babies, there was no difference between babies given sponge and tub bathing for cord infection and bacterial colonization. In our study, infection signs such as discharge and erythema were probably due to the fact that umbilical cord remained wet in babies given tub bathing (19-21).

It was determined that the time of separation of umbilical cord in babies given sponge bathing was shorter than those given tub bathing,

While no infection finding was found in 49 babies given sponge bathing, signs of discharge and erythema were seen in 2 of 51 babies (3.9\%) given tub bathing and were directed to a health institution.

Since wetting the umbilical cord during tub bathing delays the separation of umbilical cord, sponge bathing is recommended for newborns until the umbilical cord falls off.

\subsection{Limitation of Study}

This study had two limitations. First, it was conducted on babies and their mothers who were only eligible for selection criteria, and may not be generalized to other babies and their mothers who were not eligible for selection criteria. Second, the results of this study were generated from a health-care unit in Turkey, and may not be generalized to other cultures or countries. Despite these limitations, key findings of the study are of value for umbilical cord care for Turkish culture.

\section{Acknowledgements}

The authors of this article would like to thank all the participants in this study.

\section{References}

1. Blencowe H, Cousens S, Mullany LC, Lee AC, Kerber K, Wall S, et al. Clean birth and postnatal care practices to reduce neonatal deaths from sepsis and tetanus: a systematic review and Delphi estimation of mortality effect. BMC Public Health. 2011;11 Suppl 3:S11.

2. Black RE, Cousens S, Johnson HL, Lawn JE, Rudan I, Bassani DG, et al. Global, regional, and national causes of child mortality in 2008: a systematic analysis. Lancet. 2010;375(9730):1969-87.

3. Lawn JE, Cousens S, Zupan J, Lancet Neonatal Survival Steering T. 4 million neonatal deaths: when? Where? Why? Lancet. 2005;365(9462):891-900.

4. Bang AT, Bang RA, Baitule SB, Reddy MH, Deshmukh MD. Effect of home-based neonatal care and management of sepsis on neonatal mortality: field trial in rural India. Lancet.1999;354(9194):1955-61.

5. Leach A, McArdle TF, Banya WA, Krubally O, Greenwood AM, Rands C, et al. Neonatal mortality in a rural area of The Gambia. Ann Trop Paediatr. 1999;19(1):33-43.

6. Vural G, Kisa S. Umbilical cord care: a pilot study comparing topical human milk, povidone-iodine, and dry care. J Obstet Gynecol Neonatal Nurs. 2006;35(1):123-8.

7. Imdad A, Mullany LC, Baqui AH, El Arifeen S, Tielsch JM, Khatry SK, et al. The effect of umbilical cord cleansing with chlorhexidine on omphalitis and neonatal mortality in community settings in developing countries: a meta-analysis. BMC Public Health. 2013;13 Suppl 3:S15.

8. Mullany LC, Darmstadt GL, Katz J, Khatry SK, LeClerq SC, Adhikari RK, et al. Risk factors for umbilical cord infection among newborns of southern Nepal. Am J Epidemiol. 2007;165(2):203-11.

9. Mullany LC, Darmstadt GL, Katz J, Khatry SK, Leclerq SC, Adhikari RK, et al. Risk of mortality subsequent to umbilical cord infection among newborns of southern Nepal: cord infection and mortality. Pediatr Infect Dis J. 2009;28(1):17-20.

10. Darmstadt GL, Dinulos JG. Neonatal skin care. Pediatr Clin North Am. 2000;47(4):757-82.

11. Cavusoglu, H. . Child health nursing.Ankara: Sistem Offset Publishing; 2004.

12. Toruner E, Buyukgonenc L. Child health and basic nursing aspects.Ankara: Gokce Publishing; 2012

13. Rush J. Cleaning the umbilical cord with water rather than alcohol shortened the time to separation with no change in colonisation. Evid Based Nurs.1998;1(4):112.

14. A.A.P. Patient Education Online. editor. USA: American Academy of Pediatrics; 2013.

15. Lund CH, Osborne JW, Kuller J, Lane AT, Lott JW, Raines DA. Neonatal skin care: clinical outcomes of the AWHONN/NANN evidencebased clinical practice guideline. Association of Women's Health, Obstetric and Neonatal Nurses and the National Association of Neonatal Nurses. J Obstet Gynecol Neonatal Nurs. 2001;30(1):41-51.

16. Janssen PA, Selwood BL, Dobson SR, Peacock D, Thiessen PN. To dye or not to dye: a randomized, clinical trial of a triple dye/alcohol regime versus dry cord care. Pediatrics. 2003;111(1):15-20.

17. Soofi S, Cousens S, Imdad A, Bhutto N, Ali N, Bhutta ZA. Topical application of chlorhexidine to neonatal umbilical cords for prevention of omphalitis and neonatal mortality in a rural district of Pakistan: a community-based, cluster-randomised trial. Lancet. 2012;379(9820):1029-36

18. Mukhtar-Yola M, Iliyasu Z, Wudil BJ. Survey of Umbilical Cord care and Separation time in Healthy Newborns in Kano. Nigerian JPediatr. 2011;38(4):175-81.

19. Bryanton J, Walsh D, Barrett M, Gaudet D. Tub bathing versus traditional sponge bathing for the newborn.J Obstet Gynecol Neonatal Nurs. 2004;33(6):704-12.

20. Henningsson A, Nystrom B, Tunnell R. Bathing or washing babies after birth? Lancet. 1981;2(8260-61):1401-3.

21. Hylen AM, Karlsson E, Svanberg L, Walder M. Hygiene for the newborn-to bath or to wash? J Hyg (Lond).1983;91(3):529-34. 